\begin{tabular}{|c|c|c|c|c|c|}
\hline & $\begin{array}{l}\text { Hospital, } \\
\text { mean (SD) }\end{array}$ & $\begin{array}{l}\text { Home, mean } \\
\text { (SD) }\end{array}$ & $\begin{array}{l}\text { Difference, } \\
\text { mean }(95 \% \mathrm{CI})^{*}\end{array}$ & SDD & ICC $(95 \% \mathrm{CI})$ \\
\hline \multicolumn{6}{|c|}{ Rheumatoid arthritis (RA) } \\
\hline HAQ (0-3) & $\begin{array}{l}0.580 \\
(0.499)\end{array}$ & $\begin{array}{l}0.619 \\
(0.531)\end{array}$ & $\begin{array}{l}-0.040 \\
(-0.283,0.204)\end{array}$ & 0.244 & $\begin{array}{l}0.984 \\
(0.962,0.994)\end{array}$ \\
\hline VAS pain, $\mathrm{mm}$ & $\begin{array}{l}25.5 \\
(24.2)\end{array}$ & $\begin{array}{l}24.2 \\
(23.8)\end{array}$ & $\begin{array}{l}1.3 \\
(-15.3,17.7)\end{array}$ & 16.4 & $\begin{array}{l}0.969 \\
(0.927,0.987)\end{array}$ \\
\hline VAS fatigue, $\mathrm{mm}$ & $\begin{array}{l}35.6 \\
(30.4)\end{array}$ & $\begin{array}{l}33.1 \\
(30.3)\end{array}$ & $\begin{array}{l}2.4 \\
(-15.8,20.7)\end{array}$ & 18.2 & $\begin{array}{l}0.975 \\
(0.942,0.990)\end{array}$ \\
\hline VAS global, mm & $\begin{array}{l}34.0 \\
(29.8)\end{array}$ & $\begin{array}{l}34.8 \\
(30.7)\end{array}$ & $\begin{array}{l}-0.81 \\
(-18.3,15.4)\end{array}$ & 16.1 & $\begin{array}{l}0.982 \\
(0.955,0.993)\end{array}$ \\
\hline \multicolumn{6}{|c|}{ Spondyloarthritis (AS) } \\
\hline HAQ (0-3) & $\begin{array}{l}0.356 \\
(0.307)\end{array}$ & $\begin{array}{l}0.319 \\
(0.276)\end{array}$ & $\begin{array}{l}0.038 \\
(-0.215,0.290)\end{array}$ & 0.253 & $\begin{array}{l}0.947 \\
(0.868,0.979)\end{array}$ \\
\hline VAS pain, mm & $\begin{array}{l}25.2 \\
(22.6)\end{array}$ & $\begin{array}{l}23.5 \\
(21.6)\end{array}$ & $\begin{array}{l}1.7 \\
(-10.6,14.0)\end{array}$ & 12.3 & $\begin{array}{l}0.979 \\
(0.948,0.992)\end{array}$ \\
\hline VAS fatigue, $\mathrm{mm}$ & $\begin{array}{l}33.8 \\
(23.8)\end{array}$ & $\begin{array}{l}32.4 \\
(23.7)\end{array}$ & $\begin{array}{l}1.4 \\
(-11.6,14.4)\end{array}$ & 13.0 & $\begin{array}{l}0.980 \\
(0.951,0.992)\end{array}$ \\
\hline VAS global, $\mathrm{mm}$ & $\begin{array}{l}30.9 \\
(25.9)\end{array}$ & $\begin{array}{l}30.3 \\
(28.2)\end{array}$ & $\begin{array}{l}0.6 \\
(-17.3,18.4)\end{array}$ & 17.8 & $\begin{array}{l}0.972 \\
(0.930,0.989)\end{array}$ \\
\hline BASDAI, mm & $\begin{array}{l}26.0 \\
(20.7)\end{array}$ & $24.4(21.1)$ & $\begin{array}{l}1.6 \\
(-8.6,11.8)\end{array}$ & 10.2 & $\begin{array}{l}0.983 \\
(0.959,0.993)\end{array}$ \\
\hline BASFI, mm & $\begin{array}{l}27.8 \\
(22.7)\end{array}$ & $25.9(23.8)$ & $\begin{array}{l}1.9 * * \\
(-6.4,10.2)\end{array}$ & 8.3 & $\begin{array}{l}0.990 \\
(0.974,0.996)\end{array}$ \\
\hline
\end{tabular}

results comparable to results obtained from the existing touch-screen solution and were preferred by the patients.

References:

[1] Schefte et al. (2010).

Disclosure of Interest: A. E. Secher: None declared, B. Glintborg Grant/research support from: AbbVie, H. Gudbergsen Speakers bureau: MSD and Pfizer, N. Krogh: None declared, D. Jensen: None declared, I. Sørensen: None declared, R. Christensen: None declared, M. Skougaard: None declared, M. Hetland Grant/research support from: AbbVie, BMS, MSD, Pfizer, UCB, Biogen, Orion

DOI: 10.1136/annrheumdis-2017-eular.3726

\section{THU0663 SERUM GALECTIN-3 BINDING PROTEIN IS A NOVEL PREDICTOR OF VENOUS THROMBOEMBOLISM IN PATIENTS WITH SYSTEMIC LUPUS ERYTHEMATOSUS (SLE)}

A.S.R. Peretz ${ }^{1}$, N.S. Rasmussen ${ }^{2}$, N.H.H. Heegaard ${ }^{3}$, S. Jacobsen ${ }^{2}$, C. Sjöwall ${ }^{4}$, C.T. Nielsen ${ }^{2} .{ }^{1}$ Centre for Rheumatology and Spine Diseases, Gentofte, Copenhagen University Hospital, Denmark., Gentofte; ${ }^{2}$ Copenhagen Lupus and Vasculitis Clinic, Centre for Rheumatology and Spine Diseases, Rigshospitalet; ${ }^{3}$ Department of Autoimmunology and Biomarkers, Statens Serum Institut, Copenhagen, Denmark; ${ }^{4}$ Rheumatology/AIR, Department of Clinical and Experimental Medicine, Linköping University, Linköping, Sweden

Background: SLE patients have a marked increased risk of venous (VTE) and arterial (AT) thrombosis, which is not fully explained by traditional risk factors or the presence of anti-phospholipid antibodies. Thrombosis is a major cause of damage accrual, morbidity, and mortality in SLE. A better understanding of the pathogenesis and development of new biomarkers to identify patients at risk are needed. Recent studies link leptin and tumor necrosis factor-like weak inducer of apoptosis (TWEAK) to subclinical atherosclerosis and galectin-3-binding protein (G3BP) to type I interferon activation and a pro-thrombotic environment.

Objectives: To explore G3BP, interferon gamma-induced protein 10 (IP-10), soluble CD163 (sCD163), TWEAK, and leptin serum levels as predictors of venous and arterial thrombotic events, damage accrual, and all-cause mortality during long-term follow-up in a large cohort of Swedish SLE patients.

Methods: Baseline clinical and paraclinical data including disease activity and damage scores (SLICC) were available from 167 SLE patients. VTE (deep vein thrombosis and/or pulmonary embolism) and AT (myocardial infarction and/or cerebrovascular incident) data were available with a median follow-up period of six years. Baseline serum G3BP, IP-10, sCD163, TWEAK, and leptin were quantified using ELISA. Univariate and multivariate analyses were conducted to asses associations between the serum biomarkers and the occurrence of VTE/AT, damage accrual, and death.

Results: In the follow-up period 11 (7\%) VTE and $12(7 \%)$ AT events occurred. SLICC-scores increased in 79 (47\%) patients, and $19(11 \%)$ patients died. In the univariate $\mathrm{Cox}$ regression analysis G3BP levels were significantly associated with an increased risk of VTE (hazard ratio $(\mathrm{HR}) 1.10,95 \%$ confidence interval $(\mathrm{Cl})$ : $1.01-1.2, P=0.03)$. This persisted in the multivariate cox regression analyses when adjusting for age, gender, diabetes, antiphospholipid syndrome, and treatment with warfarin ( $\mathrm{HR} 1.16,95 \% \mathrm{Cl}: 1.04-1.31, P=0.01)$. None of the other serum biomarkers were associated with AT and VTE. No significant associations were observed between the biomarkers and changes in SLICC-scores or all-cause mortality.

Conclusions: Our study identifies serum G3BP as a novel independent predictor of VTE in SLE. This may improve our understanding of VTE pathogenesis in SLE and aid future VTE risk stratification and prophylaxis. Further studies are needed to translate this into clinical practice.

Disclosure of Interest: None declared

DOI: 10.1136/annrheumdis-2017-eular.4287

\section{THU0664 TRANSLATION, CULTURAL ADAPTATION AND VALIDATION OF THE SYSTEMIC LUPUS ACTIVITY QUESTIONNAIRE (SLAQ) IN A COHORT OF ITALIAN PATIENTS WITH SYSTEMIC LUPUS ERYTHEMATOSUS (SLE)}

C. Tani ${ }^{1}$, R. Vagelli ${ }^{2}$, L. Carli ${ }^{2}$, C. Stagnaro ${ }^{1}$, F. Drago ${ }^{1}$, V. Lorenzoni ${ }^{3}$, G. Turchetti ${ }^{3}$, M. Mosca ${ }^{1} .{ }^{1}$ Rheumatology Unit, University of Pisa, Pisa, Italy; ${ }^{2}$ Via Roma 67, Pisa, Rheumatology Unit, University of Pisa; ${ }^{3}$ Institute of Management, Scuola Superiore Sant'Anna, Pisa, Italy

Background: Evaluation of disease activity is one of the most important assessments in SLE; several instruments have been developed based on clinical and laboratory information recorded by the physician. Patient-administered questionnaires provide useful information with significant time and cost saving. Indeed, patient-reported outcomes are gaining a central role as outcome measures.SLAQ is a patient-reported instrument for the assessment of disease activity in SLE. It consists of three scores: Patient Global Assessment question (PGA) about presence and severity of lupus activity over the past month, questions on 24 symptoms (SLAQscore) and a single Numerical Rating Scale (NRS) for disease activity $(0-10)$.

Objectives: The aim of the study was to translate and to validate the SLAQ in Italian.

Methods: The process of translation and cultural adaptation followed published guidelines (1). The final version of the questionnaire (SLAQit) was pretested in a group of 35 SLE patients to assess acceptability, comprehension and feasibility. The validity of the SLAQit was evaluated by its administering to consecutive SLE patients attending the outpatient's clinic or the inpatients wards. Internal consistency between the three components of the score was evaluated by Chronbach's alpha; the external validity was tested toward validated activity indices (SLEDAI and ECLAM) scored by a physician blinded to the SLAQ results. In a subgroup of 30 patients the questionnaire was administered twice at 2 weeks' interval to assess its reliability.

Results: 137 patients were enrolled (92\% female, mean age 43.1 years, mean disease duration 15.3 years). At enrollment, the median SLEDAI score was 2 (range $1-18$ ) and $45 \%$ of patients had at least one organ damage (median 2 , $1-8)$. The pilot test provided a good acceptability $(99.9 \%$ of response rate) and feasibility (mean of $4.6 \pm 2.3$ minutes to be completed, 1-10); moreover, the $100 \%$ of patients declared to comprehend the scope of the SLAQ and $67.5 \%$ declared no content comprehension problems. Internal consistency was very good between (NRS vs PGA vs SLAQscore $(\alpha=0.79)$. NRS and PGA showed a linear correlation with both ECLAM and SLEDAI scores $(\rho=0.24, p=0.004$ and $\rho=0.45, p<0.001$ respectively), while the correlation with the SLAQscore didn't reach the statistical significance. SLAQit showed a very high reliability by comparing the test-retest results ( $\alpha>0.8$ for NRS, PGA and SLAQscore). SLAQit scores resulted directly related to the patients age $(p=0.002)$ and the SLICC score $(p=0.003)$ while no correlation with disease duration was observed.

Conclusions: SLAQit demonstrated to be acceptable, comprehensible and feasible in our routine clinical setting; it also showed good internal consistency; correlation with physician's driven instruments is weaker and the SLAQit was influenced by epidemiological and disease-related factors (i.e. damage), thus confirming that the disease perception from the patient's perspective can be different from physicians and influenced by several factors. The SLAQit can be considered a useful screening tool for the first assessment of the disease activity before the standard visit.

References:

[1] Guillemin F, et al. Journal of Clinical Epidemiology 1993; 46: 1417-1432.

Disclosure of Interest: None declared

DOI: 10.1136/annrheumdis-2017-eular.4207

\section{THU0665 CAN ONE GIVE UP BASDAI IN FAVOR OF ASDAS IN MONITORING SPONDYLOARTHRITIS PATIENTS ON BIOLOGICS?}

C. Cobilinschi, D. Opris-Belinski, R. Ionescu. Sfanta Maria Clinical Hospital, Bucharest, Romania

Background: Disease activity in SpA is widely evaluated through BASDAI or ASDAS with no proven superiority between the two, in spite the more objective evaluation of ASDAS through the inflammatory markers.

Objectives: The aim of this study was to evaluate the clinical quality and discriminating power between the above indices when subdividing patients with anti-TNF therapy according to their disease status indicated by BASDAI, ASDAS or PtGA.

Methods: This prospective, observational study included 100 patients with definite SpA on biological therapy.Demographic, clinical and laboratory data was collected. Statistical analysis was performed with SPSS 20.0.

Results: When used as an external criterion PtGA showed that $12 \%$ of patients had active disease with a PtGA of over 5 while $88 \%$ were classified as low disease activity.Mean ASDAS-CRP and ASDAS-ESR in the active group were 3.39 and 3.24.Mean BASDAI score in the high activity group according to PtGA was 5.66. We showed that both ASDAS scores had good discriminating capacities, with similar values when using the SMD $(2.0034[95 \% \mathrm{Cl} 1.29-2.71])$. Based on PtGA,BASDAl outperformed ASDAS scores with a SMD of $3.3391[95 \% \mathrm{Cl}$ 2.5334-4.1447]. ROC curves of the disease activity scores by using the PtGA $\geq 5$ 